\title{
Regulatory B Cells Normalize CNS Myeloid Cell Content in a Mouse Model of Multiple Sclerosis and Promote Oligodendrogenesis and Remyelination
}

\author{
Andrea Pennati, ${ }^{1}$ Emily A. Nylen, ${ }^{1}$ Ian D. Duncan, ${ }^{2}$ and ${ }^{\circledR}$ Jacques Galipeau ${ }^{1}$ \\ ${ }^{1}$ Department of Medicine, University of Wisconsin, School of Medicine and Public Health, University of Wisconsin Carbone Cancer Center, \\ Madison, WI 53706, and ${ }^{2}$ Department of Medical Sciences, School of Veterinary Medicine, Madison, WI 53706
}

The unmet medical need of patients with multiple sclerosis (MS) is the inexorable loss of CNS myelin and latterly neurons leading to permanent neurologic disability. Solicitation of endogenous oligodendrocytes progenitor cells, the precursor of oligodendrocytes, to remyelinate axons may abort the onset of disability. In female mice with experimental autoimmune encephalomyelitis (EAE), a murine model of MS, adoptive transfer of $\mathrm{IL}-10^{+}$regulatory $\mathrm{B}$ cells $\left(\mathrm{B}_{\text {regs }}\right)$ has been shown to reverse EAE by promoting the expansion of peripheral and CNS-infiltrating IL- $10^{+} T$ cells. Here, we examined whether $B_{\text {regs }}$ treatment and its bystander effect on regulatory T cells are associated with CNS repair as reflected by oligodendrogenesis and remyelination. We have found that transfusion of $B_{\text {regs }}$ reverses established clinical EAE and that clinical improvement is associated with a significant increase in spinal cord remyelination as reflected by g-ratio analysis within the thoracic and lumbar spine. We further observed in the spinal cords of EAE $\mathrm{B}_{\text {regs }}$-treated mice that CNS resident $\mathrm{CD} 11 \mathrm{~b} / \mathrm{CD} 45^{\text {int }} \mathrm{Ly} 6 \mathrm{C}^{-}$ microglia, and infiltrating $\mathrm{CD} 11 \mathrm{~b}^{+} / \mathrm{CD} 45^{\text {high }}$ monocytes/macrophages content reverts to normal and polarize to a M2-like $\mathrm{CD}^{206^{+}}$phenotype. Concurrently, there was a substantial increase in neo-oligodendrogenesis as manifest by an increase in $\mathrm{CD}^{4} 5^{-/ \text {low }}$ CNS cells expressing A2B5, an early marker in oligodendrocytes progenitor cell differentiation as well as $\mathrm{GalC}^{+} /$ $\mathrm{O1}^{+}$premyelinating and myelin basic protein ${ }^{+} /$myelin oligodendrocyte glycoprotein ${ }^{+}$mature oligodendrocytes with reciprocal downregulation of paired related homeobox protein 1 . These results demonstrate that the clinical benefit of $B_{\text {regs }}$ is associated with normalization of CNS immune milieu and concurrent activation of oligodendrocyte progenitor cells with subsequent remyelination.

Key words: $\mathrm{B}_{\text {regs; }}$; myelin; oligodendrocytes; remyelination

Significance Statement

In multiple sclerosis patients, demyelination progresses with aging and disease course, leading to irreversible disability. In this study, we have discovered, using a mouse model of multiple sclerosis, that the transfusion of autologous regulatory B cells $\left(B_{\text {regs }}\right)$ is able to ameliorate, cure, and sustain the durable remission of the disease. We show that the adoptive transfer of $B_{\text {regs }}$ dramatically decreased the frequency of myeloid-derived cells, both infiltrating monocytes/macrophages and resident microglia, and converted their phenotype to an immunosuppressive-like phenotype. Moreover, we showed that CNS oligodendrocyte progenitor cells are activated following $\mathrm{B}_{\text {regs }}$ treatment and differentiate into myelinating oligodendrocytes, which results in neo-oligodendrogenesis and remyelination of spinal cords.

Received Nov. 28, 2019; revised Apr. 3, 2020; accepted May 13, 2020.

Author contributions: A.P., I.D.D., and J.G. designed research; A.P. and E.A.N. performed research; A.P., E.A.N., I.D.D., and J.G. analyzed data; A.P. wrote the first draft of the paper; A.P., I.D.D., and J.G. edited the paper; A.P. and J.G. wrote the paper.

This work was supported by National Institutes of Health R01Al093881. We thank Benjamin August and Randall Massey for generating histology and electron microscopy samples and the technical support during transmission electron microscopy data collection at the Electron Microscope Facility at University of Wisconsin.

The authors declare no competing financial interests.

Correspondence should be addressed to Jacques Galipeau at jgalipeau@wisc.edu.

https://doi.org/10.1523/JNEUROSCI.2840-19.2020

Copyright $\odot 2020$ the authors

\section{Introduction}

Multiple sclerosis (MS) is a chronic inflammatory demyelinating disease of the CNS, progressive and often debilitating (Dendrou et al., 2015). More than 2.5 million people have been diagnosed worldwide with MS, and in the United States alone, 200 new cases of MS are diagnosed each week (Hemmer et al., 2015; Axisa and Hafler, 2016).

MS involves an abnormal immune-mediated process against the CNS (Lemus et al., 2018). Within the CNS, the activated immune system causes inflammation and damage to the myelin sheaths that surround axons (Dendrou et al., 2015; Axisa and 
Hafler, 2016; Lemus et al., 2018). Axons that have been demyelinated tend to atrophy and may eventually degenerate causing neuronal loss (Azodi et al., 2017).

There are different phenotypes of the disease, but etiologically they are all characterized by two distinct phases (Kalincik, 2015; Katz Sand, 2015; Vidal-Jordana and Montalban, 2017). At the beginning, the peripheral immune system drives the disease targeting the CNS, whereas in the progressive phase, an immune reaction within the CNS is found (Hemmer et al., 2015).

More than half a dozen disease-modifying therapies have been FDA-approved and offer a broad range of options in treating relapsing-remitting MS (Cree and Hartung, 2016; Ingwersen et al., 2016; Soelberg Sorensen, 2017). All these drugs lessen the symptoms in patients and keep the disease from getting worse by targeting the aberrant immune response but failed to prevent progression of the disease (Soelberg Sorensen, 2017). Unfortunately, there is no cure for MS, and none of these therapies can repair neurologic damage already sustained. Thus, an urgent and unmet medical need is the development of myelin repair promoting therapies for MS, the central process in the development of MS. By regenerating the myelin sheath around axons, neuronal function can be restored and prevent further neuronal loss and clinical disability (Chamberlain et al., 2016; Bove and Green, 2017; Scolding et al., 2017).

In the CNS, oligodendrocytes are the myelinating cells (Bradl and Lassmann, 2010). Oligodendrocytes wrap layers of highly specialized cell membrane around the nerve fibers to form myelin, which facilitate axonal conduction by providing electrical insulation (Dimou and Simons, 2017). Oligodendrocyte progenitor cells (OPCs) are able to migrate within the parenchyma and extend cell membrane protrusions that finally produce the insulating sheaths of neuronal axons (Bradl and Lassmann, 2010; Domingues et al., 2018). In MS, remyelination can be extensive but diminishes with aging and disease course (Goldschmidt et al., 2009). Demyelinated axons are more at risk for degeneration and can end with axon loss (Hagemeier et al., 2012). The driving force for OPC morphologic maturation and migration is still unclear but represents a major interest in demyelinating diseases, such as MS.

In mice with experimental autoimmune encephalomyelitis (EAE), a murine model of MS, we previously showed that intravenous administration of autologous regulatory $B$ cells $\left(B_{\text {regs }}\right)$ led to complete and long-lasting EAE remission that was dependent on $\mathrm{B}_{\text {regs }}$ expression of MHCII and IL-10 (Rafei et al., 2009; Pennati et al., 2016). We further defined that, following intravenous delivery, $\mathrm{B}_{\text {regs }}$ migrate to spleen and mesenteric lymph nodes and do not home to CNS. Within these secondary lymphoid organs, $\mathrm{B}_{\text {regs }}$ trigger an expansion of $\mathrm{CD} 4{ }^{+}$IL-10-expressing $\mathrm{T}$ cells that latterly accumulate in CNS coincidentally with normalization of microglial and macrophage content (Pennati et al., 2016). As an aggregate, these data showed that $\mathrm{B}_{\text {regs }}$ deploy an innate antiinflammatory response through peripheral interplay with IL-10expressing T cells that secondarily home to inflamed CNS. In this study, we have established that amelioration of EAE symptoms is accompanied by maturation of oligodendrocytes and remyelination of spinal cord in the animals treated with $B_{\text {regs. }}$ These data support the hypothesis that transfusion of $\mathrm{B}_{\text {regs }}$ can abate inflammation and secondarily promote neo-oligodendrogenesis in the CNS by activating OPCs. This preclinical observation serves as rationale for clinical studies examining the utility of cell therapy with autologous $B_{\text {regs }}$ for mitigating neuronal loss in MS.

\section{Material and Methods}

Ethics statement. All animals were handled and treated according to the guidelines and recommendations of the
Research Animal Resources Center and the Animal Care and Use Committee at the University of Wisconsin-Madison. C57BL/6 mice were purchased from The Jackson Laboratory. Mice were used between 6 and 20 week of age. EAE was induced in 8 - to 10 -week-old female mice. Mice were anesthetized by isoflurane and killed by transcardial perfusion with PBS.

Reagents and antibodies. Reagents and antibodies are as follows: MOG $_{35-55}$ (Sigma Millipore), incomplete Freund's adjuvant (Difco, BD), H37Ra Mycobacterium tuberculosis (Sigma Millipore), Percoll (GE Healthcare), and Ghost Dye Red 780 (Tonbo Biosciences). For the phenotypic analysis of monocytes and microglia, the following antibodies were used as per the manufacturer's recommendation: BD anti-CD11 APC (clone M1-70), BioLegend anti-CD45 BV510 (clone 30-F11), eBioscience anti-Ly6c PerCPCy5.5 (clone HK1.4), BD anti-MHCII, BD Horizon anti-CD44 V450 (clone IM7), BioLegend anti-CD274 BV711 (clone B7-H1), and BD anti-CD206 PE (clone 19.2). For oligodendrocyte analysis, the following markers were used as per the manufacturer's recommendation: R\&D Systems anti-A2B5 AlexaFluor-647 (clone \#105), R\&D Systems anti-oligodendrocyte marker O1 AlexaFluor405-conjugated antibody, Sigma Millipore anti-galactocerebroside FITC antibody (clone $\mathrm{mGalC}$ ), and Invitrogen anti-CD140 (PDGFRA) FITC (clone APA5). For Western Blotting analysis, R\&D Systems anti-myelin basic protein (MBP, clone \#932908), R\&D Systems anti-myelin oligodendrocyte glycoprotein (MOG, accession \#Q61885), and Invitrogen anti-paired related homeobox protein 1 (PRXX1) (PA5-75553) were used.

EAE induction and analysis. We induced and scored EAE, as previously described (Nicholson et al., 1995; Miller et al., 2010). Briefly, EAE was induced by subcutaneous injection of $50 \mu \mathrm{g}$ of MOG35-55 (Sigma Millipore) emulsified in complete Freund's adjuvant (Difco, BD) containing $5 \mathrm{mg} / \mathrm{ml} \mathrm{H37Ra} \mathrm{Mycobacterium}$ tuberculosis. On days 0 and 2, $100 \mathrm{ng}$ of pertussis toxin (Sigma Millipore) was administered by intraperitoneal injection. Signs of disease appeared 11-14 d post immunization (dpi).

EAE clinical scores were graded as follows: 0 , normal; 1 , flaccid tail; 2, hindlimb weakness; 3 , flaccid tail with paralysis of one front or one hindleg; 4, complete hindlimb paralysis and partial front leg paralysis; 5, tetraplegia, moribund, or death. Mice with a clinical score $\geq 0.5$ were included. Randomization of EAE mice was performed before experimental intervention to ensure the same starting average clinical score for each test group.

Generation of $B_{\text {regs }}$ and adoptive transfer. B cells were isolated from the spleen of normal C57BL/6 by negative selection (Stem Cell Technologies) and stimulated with $10 \mathrm{ng} / \mathrm{ml}$ of recombinant bacterial derived GIFT15 for 72-96 h to generate IL- $10^{+} \mathrm{B}_{\text {regs }}$ (Pennati et al., 2014, 2016). The cells were collected and washed twice with PBS. EAE mice received 5 million $B_{\text {regs }}$ or unstimulated $B$ cells in $0.1 \mathrm{ml}$ of PBS. Recipient mice administered $B_{\text {regs }}$ or control B cells by tail vein injection using a small gauge ( $28 \mathrm{~g}$ ) needle after onset of symptomatic EAE, every $7 \mathrm{~d}$ for three doses. Three independent experiments were conducted $(n=6$ mice per group).

\section{Western blot analysis}

Immune cells were isolated from spinal cords and brains of animals as described in Isolation of CNS immune cells and oligodendrocytes for flow cytometry. Cells were extracted in lysis buffer (Cell Signaling Technology) supplemented with $1 \mathrm{~mm}$ PMSF and $1 \times$ protease inhibitor (Thermo Fisher Scientific). Samples were separated by SDS-PAGE and immunoblotted for MOG (R\&D AF2439) and MBP (R\&D MAB42282) following the manufacturer' specifications. 
Histopathology. Spinal cords and brains from mice intracardially perfused with ice-cold Dulbecco's PBS without $\mathrm{Ca}^{2+}$ and $\mathrm{Mg}^{2+}$ and $2.5 \%(\mathrm{w} / \mathrm{v})$ glutaraldehyde sequentially, and embedded in Epon plastic. The perfusion-fixed spinal cords were cut into small blocks, further fixed with $2.5 \%$ glutaraldehyde. Semithin sections $(1 \mu \mathrm{m})$ were stained for myelin with $1 \%$ toluidine blue/1\% sodium borate. For electron microscopy, the plastic-embedded spinal cord was cut at $80 \mathrm{~nm}$. Sample preparation and tomographic electron microscopy was conducted at the University of Wisconsin, Medical School Electron Microscopy Facility with a Philips CM120 transmission electron microscope and images captured with a BioSprint 12 series digital camera using AMT Image Capture Engine V700.

Isolation of CNS immune cells and oligodendrocytes for flow cytometry. Mice $(n=3)$ were perfused intracardially with icecold Dulbecco's PBS without $\mathrm{Ca}^{2+}$ and $\mathrm{Mg}^{2+}$. Brains and spinal cords were collected and immediately homogenized with a plunger in RPMI medium. The cell suspension was centrifuged at $300 \times g$ for $5 \mathrm{~min}$ at room temperature. The supernatant was aspirated, and cells were gently resuspended in Accutase for $30 \mathrm{~min}$ at $37^{\circ} \mathrm{C}$. After centrifugation at $300 \times g$ for $5 \mathrm{~min}$ at room temperature, supernatant was discarded and the cell pellet was resuspended in $40 \%$ Percoll in HBSS (GE Healthcare). The cell suspension was centrifuged at $650 \times g$ for $25 \mathrm{~min}$, with slow acceleration and deceleration rates. Cells were isolated from the pellet and washed twice with FACS buffer. Cells are streamed through the flow cytometer, excited by laser light, and emitted fluorescence is directed throughout filters to photomultiplier tubes specific for each fluorochrome. Single cells are then analyzed using forward and side scatter of light. Further discrimination is allowed by the use of different fluorochromes. For the detection of cell surface markers, cells were stained in FACS buffer with the different fluorochrome-labeled monoclonal antibodies. Cells were incubated for $30 \mathrm{~min}$ on antibodies at $4^{\circ} \mathrm{C}$. Flow cytometry analysis and data acquisition were performed using an Attune NxT flow cytometer (Thermo Fisher Scientific), and the data analysis was performed with FCS express (DeNovo Software).

Experimental design and statistical analysis. The primary aim of this study was to determine the remyelinating properties of $\mathrm{B}_{\text {regs }}$ into EAE mice recipient. We estimated the within-group $\mathrm{SD}$ in g-ratio to be no larger than 0.0217. With $\alpha=0.05$, and the $\mathrm{SD}$ as above, a power of 0.9 can be met to detect a difference of 0.05 or more in mean g-ratio between any two experimental groups with a sample size of $n=6$ mice per group. g-ratio values are visualized as data displayed as box and whiskers (Min to Max).

For flow cytometry validation experiments, EAE was induced in WT mice as previously described and were killed at early onset (13 dpi), onset ( $21 \mathrm{dpi}$ ), and during chronic phase or remission of the disease (34 dpi). Microglia, monocytes/macrophages, and OPCs were isolated and labeled with the appropriate antibody as previously described. Dead cells were eliminated using a LIVE/ DEAD staining dye (Ghost Dye Red 780, Tonbo Biosciences). Flow cytometry was performed on Attune NxT flow cytometer (Thermo Fisher Scientific), and the data analysis was performed with FCS express (DeNovo Software). Each sample was derived from a single mouse, and at least 6 mice were used in each group.

For the Western blotting analysis, each sample was derived from a pool of 3 or 4 mice.

All statistical analyses were performed using Prism 6 Software. Unless otherwise indicated, tests of statistical significance were conducted using a two-tailed Student's $t$ test. Data display normal variance. The threshold for significance for all experiments was set at $p<0.05$. In bar graphs, all data are plotted as mean \pm SEM.

\section{Results \\ Histologic analysis of spinal cords from EAE mice following $B_{\text {regs }}$ transfusion}

To test the hypothesis that $\mathrm{B}_{\text {regs }}$ can ameliorate EAE by inducing remyelination, $\mathrm{C} 57 \mathrm{BL} / 6$ female mice were immunized with $\mathrm{MOG}_{35-55}$ peptide to develop a chronic form of EAE. After 10$13 \mathrm{~d}$, the mice displayed clinical signs and were allocated in three groups having a similar average clinical score $(1.6 \pm 0.5)$. Six untreated EAE mice were killed $13 \mathrm{dpi}$ (Fig. 1A). The other two groups of EAE C57BL/6 mice were injected intravenously starting $13 \mathrm{dpi}$ either with $2 \times 10^{6} \mathrm{~B}_{\text {regs }}(n=6)$ or $2 \times 10^{6} \mathrm{~B}$ cells $(n=6)$ every $7 \mathrm{~d}$ for 3 weeks, and the disease score was followed over time (Fig. 1A). Clinical attenuation of the disease score was observed in mice treated with $B_{\text {regs }}$ with a clinical score on day 40 dpi of $0.1 \pm 0.1$. EAE mice treated with control B cells had an average score of $1.8 \pm 0.4$, similar to untreated EAE mice with an average score of $1.9 \pm 0.5$ (Rafei et al., 2007; Pennati et al., 2016).

Spinal cords of untreated animals were collected 13 dpi or 2.53 weeks after the first adoptive transfer of $B$ cells or $B_{\text {regs. }}$. Toluidine blue staining of spinal cord sections (Fig. $1 B$ ) was used to screen sections of the spinal cords to evaluate the areas for remyelination/demyelination. Both areas were manually outlined and calculated by an automated system with ImageJ. Demyelination and remyelination areas were observed in the spinal cord white matter following EAE induction (Fig. 1B). Spinal cords of WT mice showed no signs of demyelination (Fig. 1B). Mice treated with control B cells underwent progressive demyelination as shown by the areas of the spinal cords with faint staining (Fig. 1B). Demyelination was evident in the lateral column of the thoracic sections, but they were qualitatively more pronounced in the subpial ventrolateral column of lumbar sections of mice treated with B cells (Fig. 1B). Untreated EAE mice showed lesions in the spinal cords (Fig. 1B). The lesions in the lumbar spinal cords of EAE-untreated mice were comparable with the one observed in EAE B-cell-treated mice 1 month after treatment (Fig. 1B,C). In the thoracic region always of untreated EAE animals, smaller demyelinated lesions were detectable compared with B-cell-treated animals (Fig. 1B,C). However, mice treated with $B_{\text {regs }}$ showed more homogeneous staining of the spinal cords with toluidine blue (Fig. $1 B$ ). The percentage of spinal cord regions affected by EAE lesions varied greatly between the three different groups, even within the same sample, and the most severe lesions appeared to be more caudal in the spinal cord (Fig. 1C). Indeed, the demyelination observed in MOG-immunized mice is not homogeneous throughout the spinal cord and/or between different mice. Analysis of the spinal cords of $\mathrm{B}_{\text {regs }}$-treated animals that went to full remission did not show evidence of lesions in toluidine blue-stained sections, consistent with myelin integrity similar to that observed in control WT animals (Fig. 1B).

\section{Transmission electron microscopy of myelin sheaths and g- ratio on spinal cord sections}

To examine the effect of $B_{\text {regs }}$ adoptive transfer on spinal cord myelin sheath distribution in EAE, ultrastructural analyses of the spinal cords were conducted by transmission electron microscopy (TEM) (Fig. 2A,B). Six $\mathrm{B}_{\text {regs }}$-treated and six B-cell-treated EAE C57BL/ 6 mice were killed 3.5 weeks after adoptive transfer concomitant to near-complete clinical recovery (average disease score of $0.1 \pm 0.1$ ) of the animals treated with $B_{\text {regs }}$ compared 
A

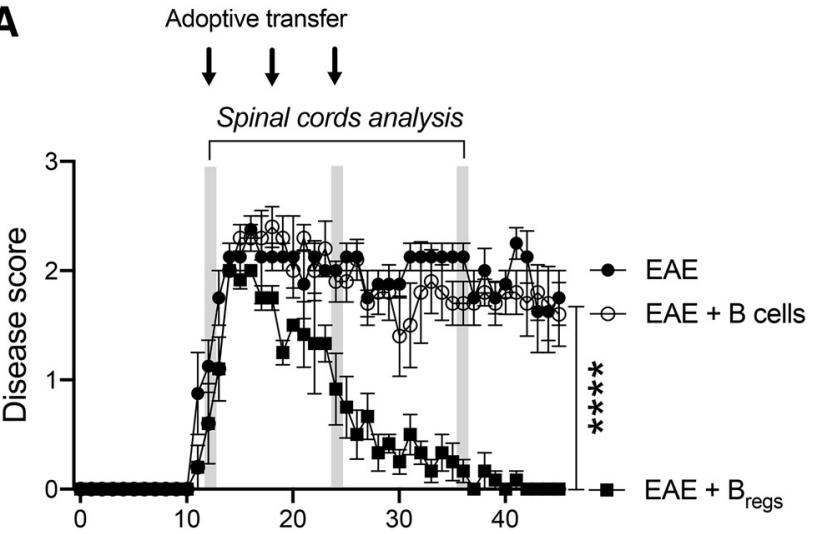

Time (days) after immunization

B
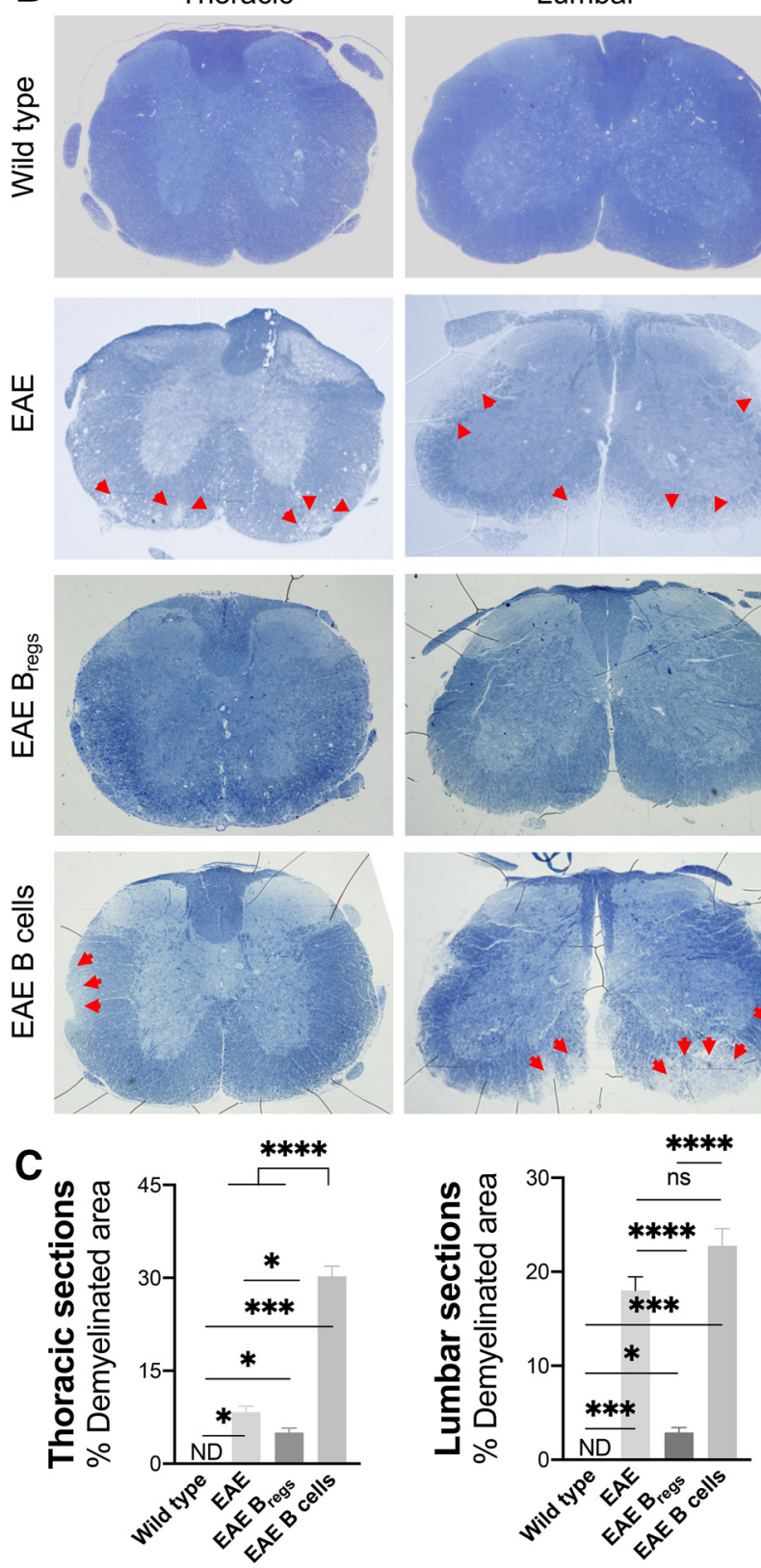

Figure 1. Adoptive transfer of $B_{\text {regs }}$ or $B$ cells in EAE mice and spinal cord myelination. $A$, Disease progression and clinical score in three cohorts of EAE C57BL/6 mice: untreated, treated with $B_{\text {regs, }}$ or $B$ cells $(n=6)$. Arrows indicate the adoptive transfer of $2 \times 10^{6} B_{\text {regs }}$ with B cells controls (average disease score of $1.8 \pm 0.6$, $p<0.0001$ ). Spinal cords of four mice $13 \mathrm{dpi}$ (onset of symptoms) serve as control animals to assess cord lesions before any treatment (Fig. 2A,B). Further spinal cords of six WT mice served as a control in the absence of EAE. Low TEM set was used first to define the regions of the spinal cords (dorsal, ventral, and lateral) followed by high magnification. High-magnification examination qualitatively revealed thin myelin sheaths, a welldefined morphologic hallmark of remyelination, in mice treated with $\mathrm{B}_{\text {regs }}$ (Fig. 2A). Untreated EAE mice showed signs of demyelination similar to mice treated with B cells (Fig. 2A).

To further quantify the extent of remyelination, we measured the axon diameter/fiber diameter as reflected by the g-ratio in three different regions (lumbar, thoracic, and cervical regions of the spinal cords) (Guy et al., 1991). This ratio correlates the myelin sheath thickness to its respective nerve fiber. Mice killed at onset of disease showed signs of demyelination both in the thoracic and lumbar region with respect to WT mice (Fig. 2B; $p \leq$ $0.0001)$. $B_{\text {regs }}$-treated mice displayed significant remyelination in the thoracic and lumbar regions compared with untreated EAE mice or B-cell-treated mice, with lower g-ratio values (Fig. 2B; $p \leq 0.0001$, dorsal, ventral, and lateral regions of thoracic sections, and $p \leq 0.01$ for the lumbar sections). Mice treated with $\mathrm{B}_{\text {regs }}$ showed a g-ratio similar to the one observed on normal mice (Fig. 2B). No difference between the four groups was evident in the cervical region, and the g-ratio values were comparable with the ones observed in literature for WT animals (Fig. 2B).

\section{Analysis of CNS resident microglia and myeloid cells in EAE mice after $B_{\text {regs }}$ treatment}

Using flow cytometry analysis, we have previously showed increased frequency of macrophages/monocytes cells in the CNS of a murine model of ALS (Pennati et al., 2018). Intravenous treatment with $B_{\text {regs }}$ was able to diminish the percentage of CNS-infiltrating monocytes/macrophages compared with what observed in untreated animals. To better understand whether treatment with $\mathrm{B}_{\text {regs }}$ had any effect in the CNS-infiltrating myeloid cell composition and phenotype in EAE, spinal cords and brains were collected and analyzed for leukocyte content in cohorts of treated and control EAE mice 1 month after adoptive transfer of $B_{\text {regs. }}$.

Samples isolated with Percoll gradient were separated in two primary populations, $\mathrm{CD} 45^{\text {int }}$ and $\mathrm{CD} 45^{\text {high }}$. Differences in the surface expression of $\mathrm{CD} 45$ antigen relate to the distinction between microglia $\left(\mathrm{CD} 11 \mathrm{~b}^{+} \mathrm{CD} 45^{\text {int }} \mathrm{Ly} 6 \mathrm{C}^{-}\right)$and blood-derived myeloid cells $\left(\mathrm{CD} 11 \mathrm{~b}^{+} \mathrm{CD} 45^{\text {high }}\right)$ (Ritzel et al., 2015). In the brain, mice treated with $B_{\text {regs }}$ showed a frequency of monocytes/ macrophages similar to the one observed in normal mice $(<1 \%)$ and lower to the one detected in the B-cell-treated animals (Fig. $3 A ; p=0.03)$. An increased frequency of infiltrating monocytes/ macrophages in the B-cell-treated animals respect to the $\mathrm{B}_{\text {regs }}{ }^{-}$

$\leftarrow$

or $B$ cells. $\boldsymbol{B}$, Spinal cord analysis with toluidine blue-stained sections (thoracic and lumbar region) in WT, EAE-untreated, EAE $B_{\text {regs }}$-treated, and EAE B-cell-treated mice. Arrows indicate regions of demyelination in the spinal cord of EAE-untreated and EAE B-cell-treated animals. C, Quantitative comparison of relative lesions in EAE $B_{\text {regs }}$ or B-cell-treated mice 3.5 weeks after adoptive transfer, EAE mice $13 \mathrm{dpi}$, and WT animals. From each of the cross-sections in Figure $1 A$, the total of white matter was outlined. Lesion areas, defined as regions of white matter with demyelination or remyelination, were then traced in the same cross-sections. Data are representative of three independent experiments in vivo with $n \geq 6$. Data are mean \pm SEM. ${ }^{*} p<0.05 ;{ }^{* * *} p \leq 0.001 ;{ }^{* * * *} p \leq 0.0001$, ns, not significant or $p>0.05$; compared with the corresponding control, in 3 representative mice (Student's $t$ test). ns, not significant. 
A
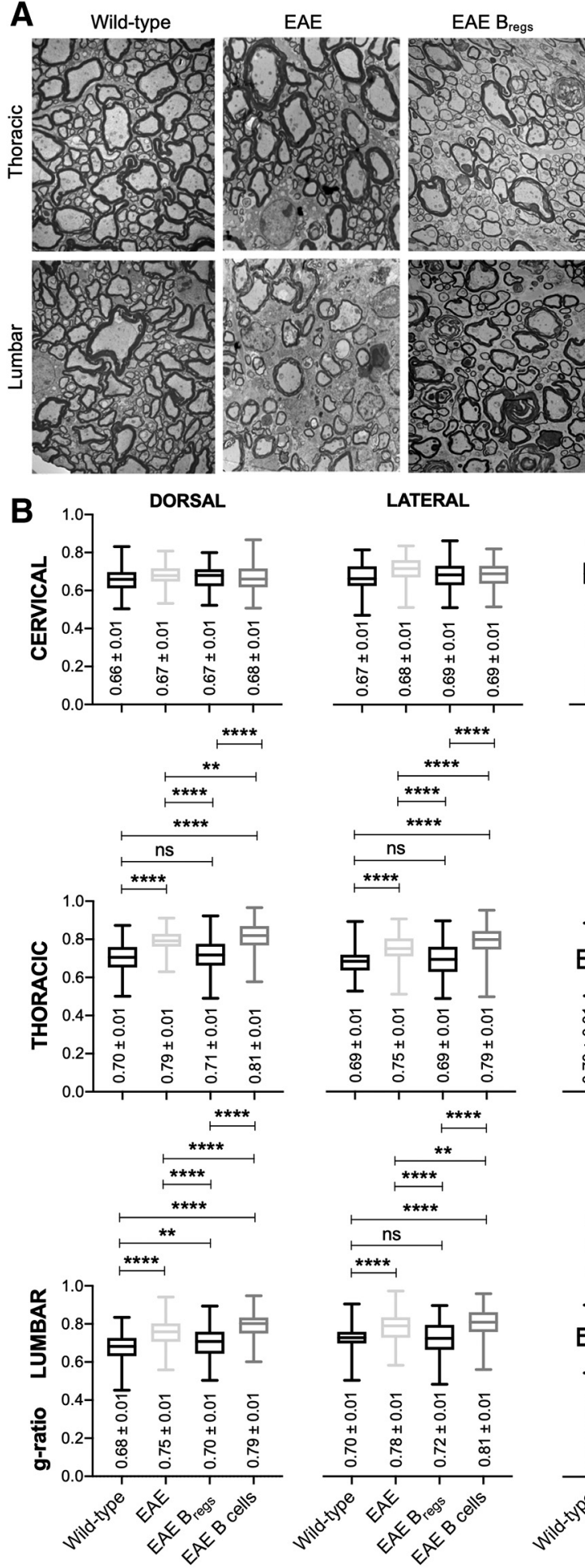

LATERAL
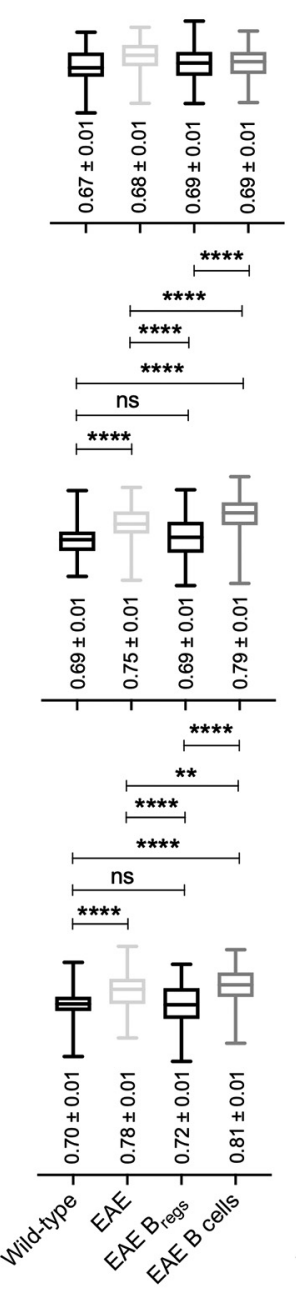

EAE B cells

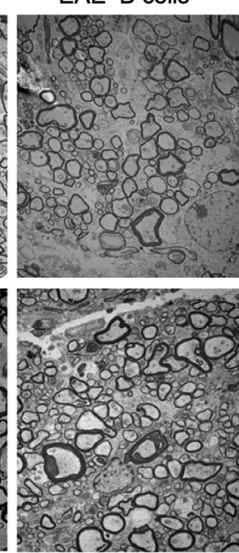

VENTRAL
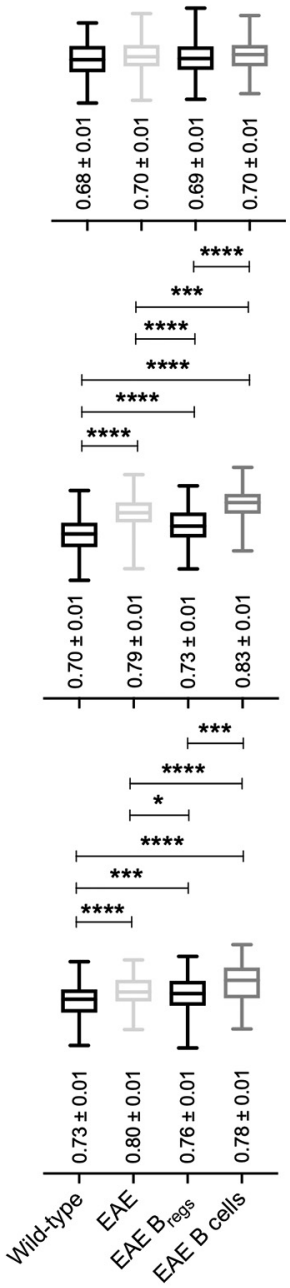

Figure 2. TEM on spinal cords of WT, EAE-untreated mice, and $B_{\text {regs }}$ or B-cell-treated EAE mice. $A$, Electron micrograph of spinal cords $(3400 \times)$, thoracic and lumbar regions of WT mice, untreated EAE mice, $B_{\text {regs, }}$ or B-cell-treated EAE mice in cross-sections. $\boldsymbol{B}$, Box plots represent $g$-ratio (diameter of the inner axon:outer diameter of myelinated fiber). Data are representative of two independent experiments in vivo with $n \geq 6$. Data are presented as box and whiskers (Min to Max). ${ }^{*} p<0.05 ;{ }^{* *} p \leq 0.01$; ${ }^{* * *} p \leq 0.001$; ${ }_{* * * *} \leq 0.0001$; compared with the corresponding control, in 4 representative mice (Student's $t$ test). ns, not significant.

treated group was evident (Fig. $3 A ; p=0.02$ ). The frequency of infiltrating monocytes/macrophages in the spinal cords of $\mathrm{B}_{\text {regs }^{-}}$ treated animal was increases with respect to the WT group but lower to the one of B-cell-treated animals (Fig. $3 A ; p=0.03$ and $p=0.02$, respectively).
Mice treated with $\mathrm{B}_{\text {regs }}$ showed a frequency of resident microglia similar to the one observed in WT mice in the brains and a 1.5 -fold increase in the spinal cords (Fig. 3C; $p=0.04$ ). However, B-cell-treated EAE animals have an increase frequency of resident microglia in the spinal cords, compared with WT animals (Fig. 3C; $p=$ 0.02 ). Similarly, higher frequency of resident microglia could be observed in the brains of the animals treated with $\mathrm{B}$ cells compared with the $\mathrm{B}_{\text {regs }}{ }^{-}$ treated group (Fig. $3 C ; p=0.03$ ).

Moreover, we conducted phenotypic analysis of infiltrating monocytes and resident microglia, both in brains and spinal cords. In brain monocytes/macrophages, a slight but significantly lower expression of CD44 was observed in the animals treated with $\mathrm{B}$ cells compared with $\mathrm{B}_{\text {regs }}$-treated animals (Fig. $3 A, B$ ). No significative differences in the expression of other proinflammatory markers were detectable, both in infiltrating monocytes/macrophages and resident microglia, neither in spinal cords nor brains of all cohorts of animals (Fig. $3 A-D$ ). We also examined the expression of CD206 as a surrogate marker of M2 polarization of myeloidderived cells either microglia or monocytes/macrophages. Both in the brains and spinal cords, a higher expression of CD206 in microglia was observable in the $\mathrm{B}_{\text {regs }}$-treated animals compared with the B-cell-treated ones (Fig. 3A-D; $p=0.002$ in the brains and $p=0.008$ in spinal cords, respectively). Similarly, a higher expression of CD206 was noticeable in the brains and spinal cords of infiltrating monocytes/macrophages in the $\mathrm{B}_{\text {regs }}$-treated group with respect to B-cell-treated animals (Fig. $3 A-D ; p<$ 0.0001 for the brains and $p=0.006$ for spinal cords, respectively). The expression levels of CD206 in the $\mathrm{B}_{\text {regs }}$-treated animal were similar to the one observed in WT animals (Fig. 3A-D).

\section{Oligodendrocytogenesis in spinal cords and brains of EAE mice} treated with $B_{\text {regs }}$

Spinal cords of C57BL/6 EAE mice, treated either with $\mathrm{B}$ cells or $\mathrm{B}_{\text {regs }}$, or naive mice were mechanically dissociated and sequentially digested with Accutase for $30 \mathrm{~min}, 2$ and 3.5 weeks after adoptive transfer. To ascertain oligodendrocyte content and OPC distribution, we performed flow cytometric analysis of nonhematopoietic cells $\left(\mathrm{CD} 45^{-/ \mathrm{low}}\right)$ from CNS and used a panel of antibodies to characterized markers expressed during different stages of oligodendrocyte 
A

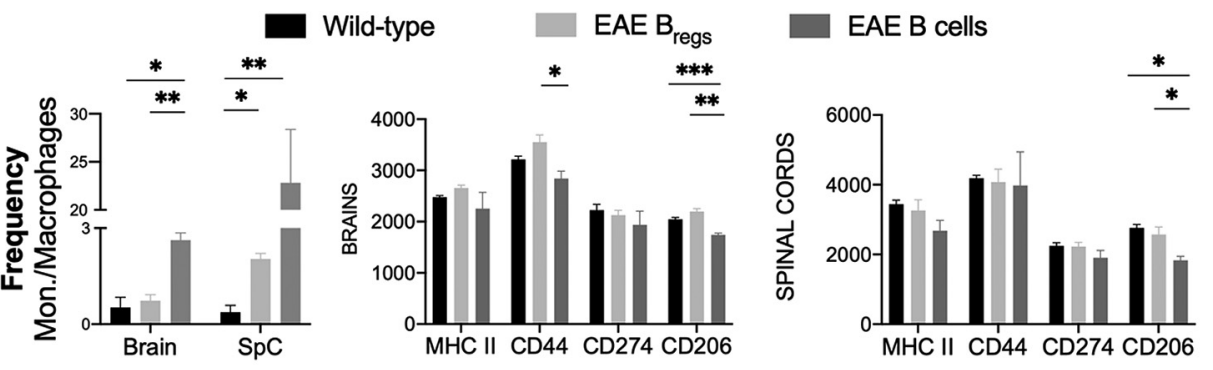

B
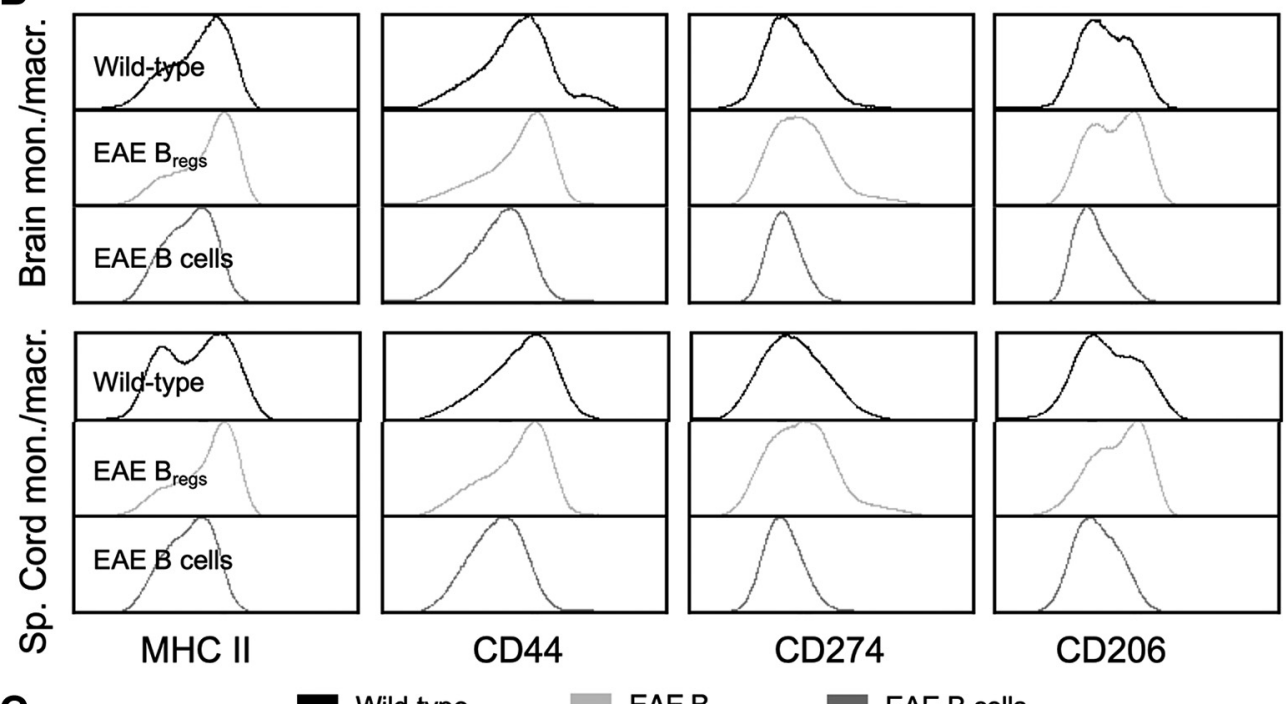

CD44

CD274

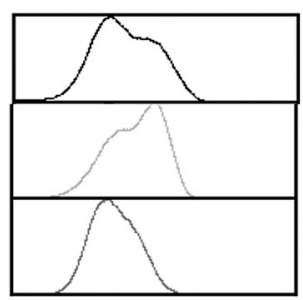

CD206

C

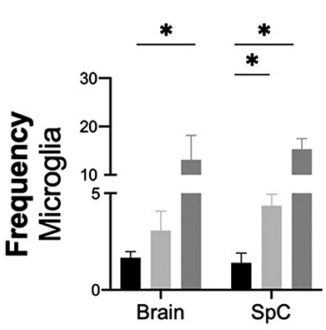

Wild-type

EAE $B_{\text {regs }}$

EAE B cells
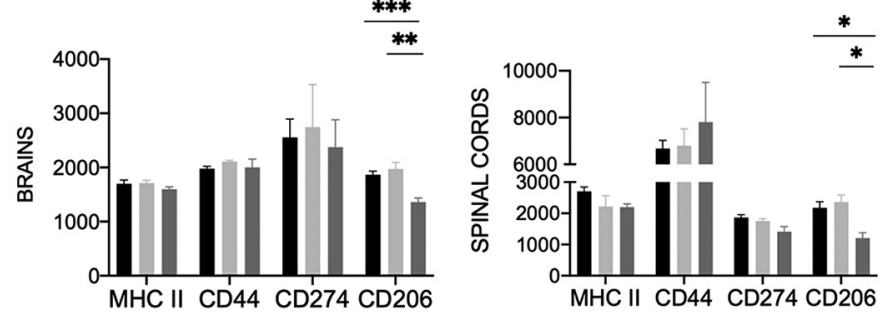

D
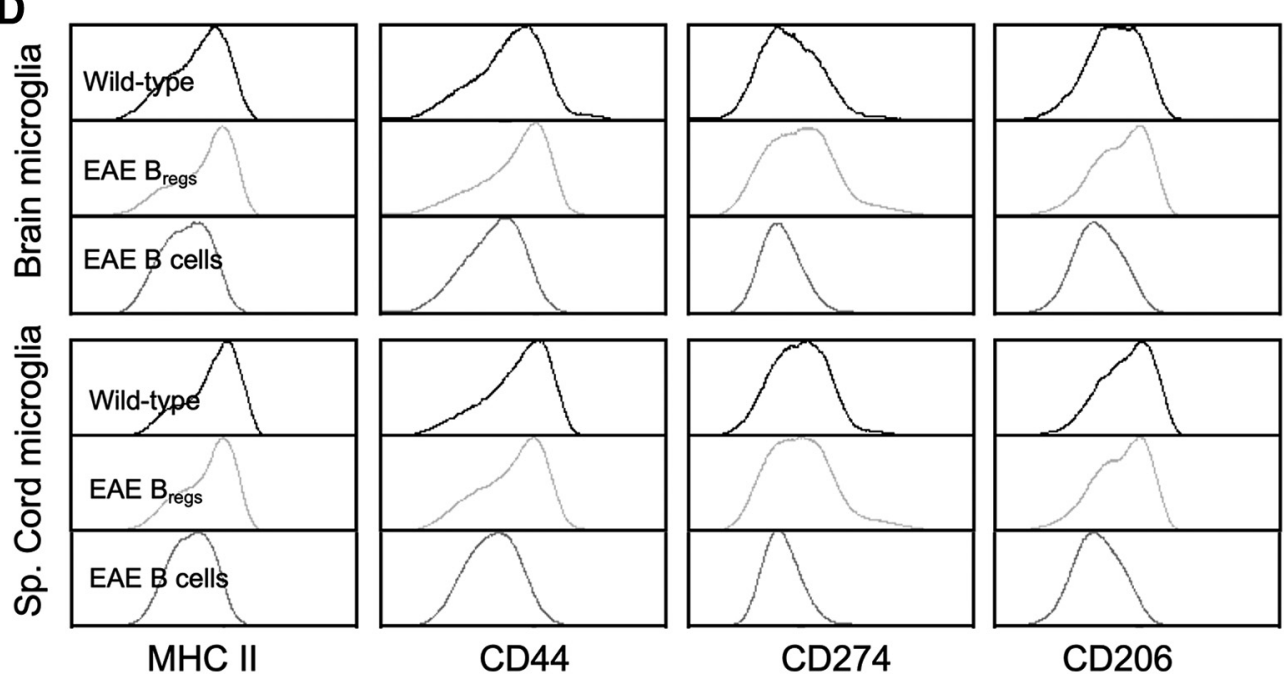

Figure 3. Flow cytometry analysis of freshly isolated CNS-infiltrating monocytes/macrophages and resident microglia after $B_{\text {regs }}$ adoptive transfer in EAE mice compared with WT animals. Content and phenotype of $(A, B)$ monocytes/macrophages $\left(C D 11 b^{+} C D 45^{\text {high }}\right.$ Ly $\left.6 c^{+}\right)$and $(C, D)$ microglia $\left(C D 11 b^{+} C D 45^{\text {int }}\right.$ Ly6 $\left.C^{-}\right)$were determined. Data are representative of two independent experiments in vivo with $n \geq 6$. Data are mean \pm SEM. ${ }^{*} p<0.05 ;{ }^{* *} p \leq 0.01 ;{ }^{* * *} p \leq 0.001$; compared with the corresponding control (Student's $t$ test). 
A

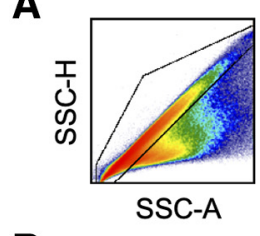

B

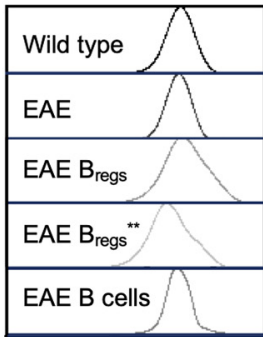

A2B5

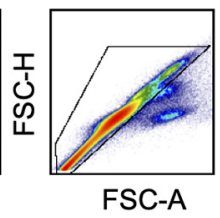

FSC-A

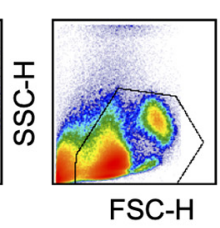

FSC-H
Ghost Red

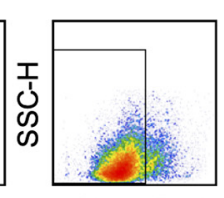

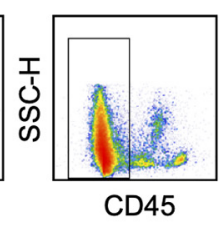

CD45

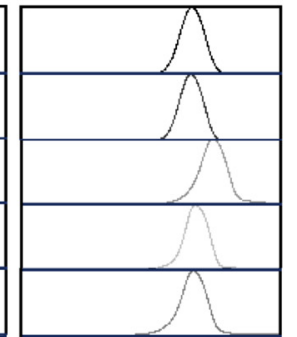

CD140

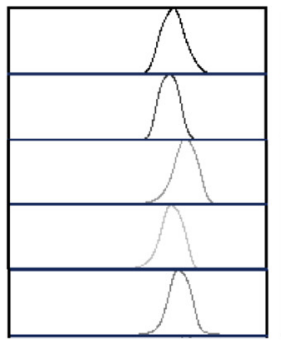

GALC

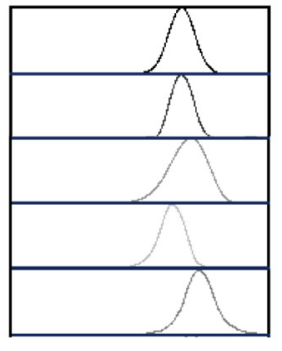

01

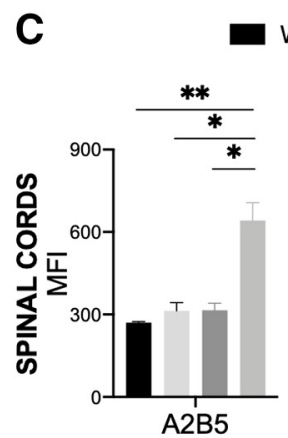

Wild-type

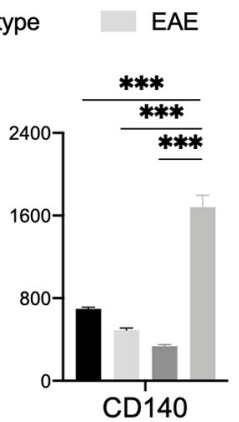

EAE B cells

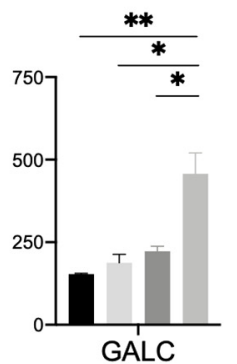

EAE $B_{\text {regs }}$
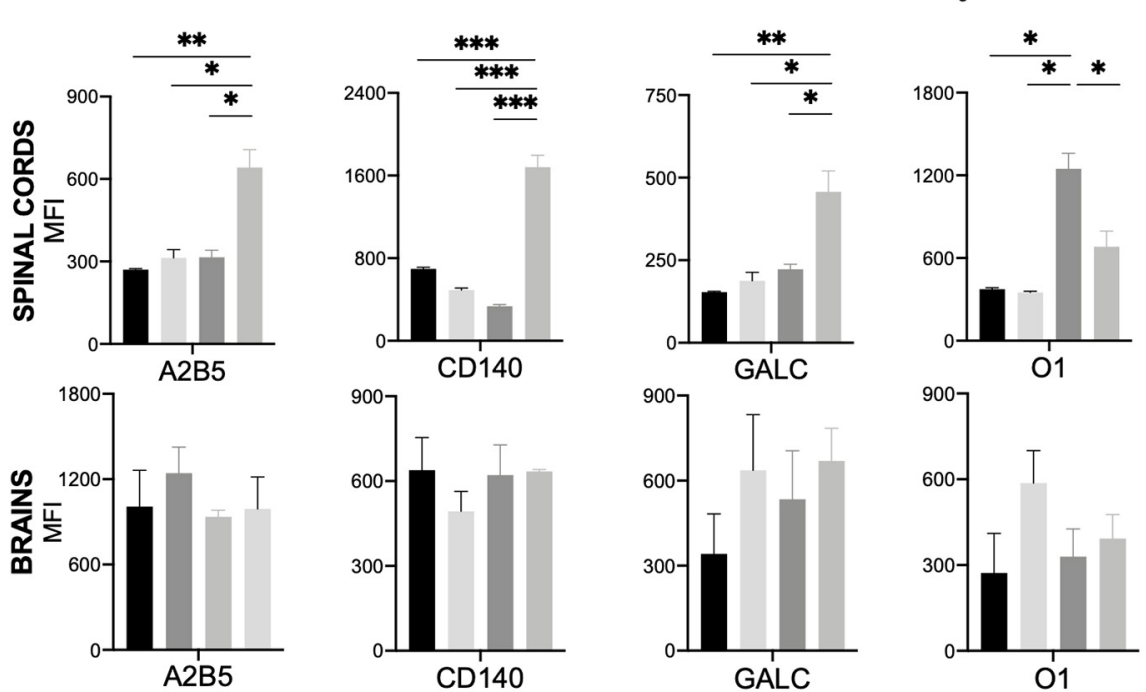
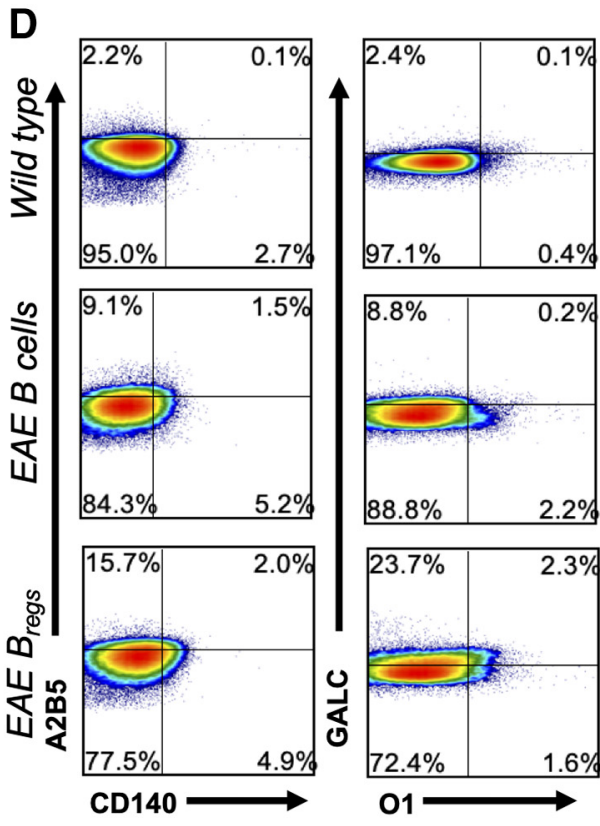

E
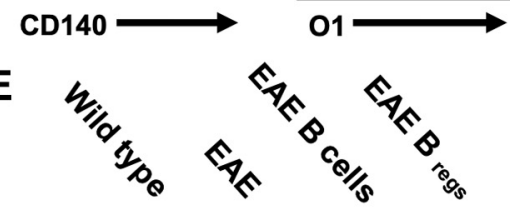

MOG

MBP

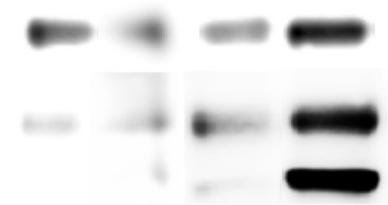

PRRX1

GADPH

Figure 4. Oligodendroglial lineage after adoptive transfer with B cells or $B_{\text {regs }}$ in EAE mice. Mice were killed starting 2 weeks after adoptive cell transfer, and spinal cords were collected for analysis by flow cytometry and Western blotting. Naive mice and untreated EAE mice were used as control. $A$, Gating strategy: single cells in side and forward scatter, cells, live cells followed by $C D 45^{-l l o w}$ gate. $B$, Expression of oligodendroglial markers 2 (and 3.5 weeks for $B_{\text {regs }}{ }^{* *}$ treated animals) after adoptive transfer with $B_{\text {regs }}$ or $B$ cells compared with WT and EAE-untreated mice: A2B5, CD140, GalC, and 01 in WT mice and EAE C57BL/6 treated either with B cells or $B_{\text {regs. }}$, Statistical analysis of the oligodendroglial marker expression in the spinal cords and brains 2 weeks after adoptive transfer. $\mathbf{D}$, Oligodendroglial phenotyping from spinal cords in $\mathrm{WT}, \mathrm{B}_{\text {regs }}$ and B-cell-treated mice: $\mathrm{A2B5}{ }^{+} \mathrm{CD} 140^{+}$, early $\mathrm{OPCs}$, and $01^{+} \mathrm{GALC} \mathrm{C}^{+}$mature oligodendrocytes. $\boldsymbol{E}$, Western blotting analysis on the expression of MOG, MBP, and paired-related homeobox protein 1 (PRXX1) by spinal cord oligodendrocytes from EAE C57BL/6 mice untreated, treated with $B_{\text {regs }}$ or B cells, and WT mice 2 weeks after adoptive transfer, load control GADPH. Data are representative of three independent experiments in vivo with $n \geq 6$. Data are mean \pm SEM. ${ }^{*} p<0.05 ;{ }^{* *} p \leq 0.01 ;{ }^{* * *} p \leq 0.001$; compared with the corresponding control (Student's $t$ test).

lineage (Robinson et al., 2014). Isolation of OPCs was conducted with $40 \%$ Percoll gradient centrifugation. Sequential gates in forward and side scatter were drawn to remove debris and other events of noninterest, preserving cells based on size and complexity. Live cells were gated on singlets, and finally the $\mathrm{CD} 45^{-/ \text {low }}$ was analyzed to exclude hematopoietic cells and microglia (Fig. 4A).

Oligodendrocyte lineage analysis from early progenitor (A2B5 and CD140) to premyelinating/myelinating oligodendrocytes (GALC and O1) was conducted by flow cytometry (Fig. $4 B$ ). In the spinal cords, within 2 weeks after adoptive transfer a twofold upregulation of A2B5 a cell surface ganglioside epitope, an early marker in OPC differentiation, can be observed in mice treated with $\mathrm{B}_{\text {regs }}$ compared with WT or B-cell-treated mice (Fig. $4 B, C ; p=0.004$ and $p=0.02$, respectively). More than twofold up regulation of CD140 was present in $\mathrm{B}_{\text {regs }}$-treated animals compared with WT mice (Fig. 4B,C; $p<0.0001$ ). Interesting, Bcell-treated mice showed a twofold downregulation of CD140 respect to WT animals (Fig. $4 B, C ; p=0.003$ ). A twofold upregulation of premyelinating oligodendrocyte marker GalC was observable in the spinal cord of $\mathrm{B}_{\text {regs }}$-treated mice compared with EAE mice treated with $\mathrm{B}$ cells or WT animals (Fig. $4 B, C$; $p<0.05$ and $p=0.009$, respectively). Oligodendrocyte Marker $\mathrm{O} 1$ was threefold upregulated in the EAE mice treated with $\mathrm{B}$ cells respective to WT mice (Fig. $4 B, C ; p=0.02$ ). Further analysis by flow cytometry showed a downregulation of GalC and $\mathrm{O} 1$ in the $B_{\text {regs }}$-treated group once the full remission of the disease was noticeable, 3.5 weeks after adoptive transfer (Fig. 4B). To further investigate OPC maturation/differentiation, the frequency of early-myelinating oligodendrocytes $\left(\mathrm{A} 2 \mathrm{~B} 5{ }^{+} \mathrm{CD} 140^{+}\right)$and premyelinating/myelinating oligodendrocytes $\mathrm{GALC}^{+} \mathrm{O}^{+}$was assessed in the spinal cords of WT and EAE B cells or $\mathrm{B}_{\text {regs }}{ }^{-}$ 
treated mice (Fig. 4C). Both $\mathrm{B}$ cell- and $\mathrm{B}_{\text {regs }}$-treated animals showed an expansion of early-myelinating double-positive $\mathrm{A} 2 \mathrm{~B} 5{ }^{+} \mathrm{CD} 140^{+}$oligodendrocytes, but only in the $\mathrm{B}_{\text {regs }}$-treated mice were fully differentiated premyelinating/myelinating double-positive $\mathrm{GALC}^{+} \mathrm{O}^{+}$oligodendrocytes detected. Indeed, in the B-cell-treated mice, the expression of both GALC and O1 is 10 -fold lower compared with the $\mathrm{B}_{\text {regs }}$-treated EAE mice $(0.2 \%$ vs $2.3 \%$ for $\mathrm{B}$ cells and $\mathrm{B}_{\text {regs }}$-treated animals, respectively; Fig. $4 D)$. These data support the hypothesis that in EAE there is a limited maturation of the previously expanded early/premyelinating OPCs (Robinson et al., 2014). No significant differences were noticeable in the expression of oligodendrocyte markers in the brain between all the four groups (Fig. 4C).

Western blotting analysis of whole spinal cord lysate were analyzed for expression of markers usually expressed in a more mature stage of oligodendrocytes development. Both MBP and MOG were increased in the spinal cords of $\mathrm{B}_{\text {regs }}$-treated animals compared with the B-cell-treated group, the EAE-untreated group, and the control, age-matched WT mice (Fig. 4E). Only in $\mathrm{B}_{\text {regs }}$-treated animals, paired related homeobox protein 1 was downregulated in the spinal cord in respect to untreated EAE mice, B-cell-treated, or normal mice (Fig. $4 E$ ).

\section{$B_{\text {regs }}$ adoptive transfer in IL-10 ${ }^{-/-}$EAE mice}

To investigate the role of host endogenous IL-10 in the therapeutic effect induced by $\mathrm{B}_{\text {regs, }}$, we induced EAE in IL- $10^{-1-}$ mice as previously described. IL-10 $10^{-1-}$ mice were more susceptible to EAE disease compared with IL-10-sufficient C57BL/6 mice and the disease itself was significantly more severe (Fig. 5A). Animals had to be killed over time due to progressive deterioration of their well-being (Fig. 5B).

After onset of EAE, the IL- $10^{-1-}$ mice received one injection per week of IL-10-sufficient $B_{\text {regs }}$ or B cells for 3 weeks. There was no amelioration of EAE disease score after adoptive transfer with $B_{\text {regs }}$ (Fig. 5A). The severity and persistence of the disease observed after adoptive transfer with $\mathrm{B}_{\text {regs }}$ suggest that host endogenous IL-10 is necessary for therapeutic effect of $B_{\text {regs }}$ in EAE animals and remyelination.

\section{Discussion}

The ability of $\mathrm{B}_{\text {regs }}$ to regulate the immune response and to mitigate EAE symptoms has been established (Mann et al., 2007; Matsushita et al., 2008). Moreover, we also have previously demonstrated that adoptive transfer of $\mathrm{B}_{\text {regs }}$ in a murine model of MS (EAE) was able to ameliorate the disease progression by inducing IL-10-producing $\mathrm{CD}^{+}{ }^{+} \mathrm{T}$ cells, including conventional FoxP3 ${ }^{+}$ $\mathrm{T}_{\text {regs, }}$ as well as FoxP3- Tr-1 cells within the CNS (Pennati et al., 2016). Interestingly, $B_{\text {regs }}$ do not home to the CNS but to secondary lymphoid organs, spleen, and lymph nodes. However, if amelioration of EAE could be attributed to immune suppression, full remission of the disease can only be accomplished with the restoration of myelin sheaths by mobilization and maturation of OPCs.

To understand whether the remission of EAE mice treated with $B_{\text {regs }}$ was accompanied by remyelination, we here performed analyses of the spinal cords with sections stained with toluidine blue and secondly with TEM. Demyelination and remyelination were observed in the spinal cord white matter of all the EAE mice. Demyelination lesions were observed throughout the lumbar and thoracic areas and contributed to the neurologic deficit of the EAE model. Additionally, spinal cord lesions were comparable in size and location in the untreated and B-cell-

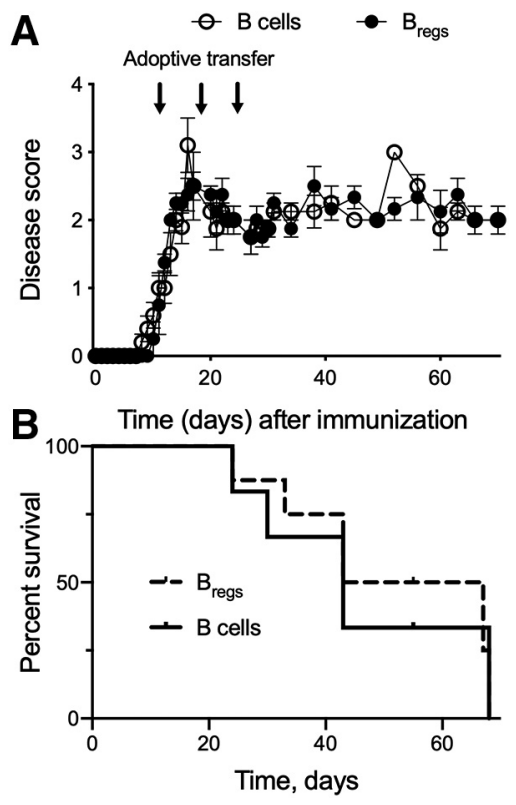

Figure 5. Effect of adoptive transfer of $B_{\text {regs }}$ in IL-10 $10^{-1-}$ EAE mice. $A$, Disease progression and clinical score in two cohorts of EAE IL- $10^{-1-}$ mice treated with $B_{\text {regs }}$ or $B$ cells. Arrows indicate the adoptive transfer of $2 \times 10^{6} B_{\text {regs }}$ or $B$ cells generated/obtained from IL-10-sufficient $\mathrm{C} 57 \mathrm{BL} / 6$ mice. $\boldsymbol{B}$, Survival curve of IL- $10^{-1-}$ mice following adoptive transfer with $B_{\text {regs }}$ or $B$ cells. Data are representative of two independent experiments in vivo with $n=6$. Data are mean \pm SEM.

treated mice. The morphologic hallmark of remyelination is proposed to be the presence of axons with thin myelin sheaths that have a significant increase in the g-ratio (axon diameter/total fiber diameter) (Franklin and Goldman, 2015). To determine whether nerve fibers in EAE mice treated with $B_{\text {regs }}$ underwent remyelination, the g-ratio was assessed. Since the percentage of spinal cord regions affected by EAE lesions varied greatly even within the same animal, cervical, thoracic, and lumbar segments of spinal cords were examined and microphotographs collected for the lateral, ventral, and dorsal area of each sections. Measured g-ratio values in the lumbar regions of untreated EAE mice at onset of the disease revealed the presence of demyelinated lesions with size and location comparable with the ones observed in EAE mice treated with B cells 3 weeks after adoptive transfer. Smaller lesions were observed in the thoracic areas of untreated EAE mice compared with B-cell-treated EAE mice. Clear findings of remyelination in $\mathrm{B}_{\text {regs }}$-treated animal were noticeable from 3.5 weeks after adoptive transfer, mainly in the lumbar and thoracic regions that correlate with recovery from hindlimb paralysis, compared with EAE mice that received $\mathrm{B}$ cells. Moreover, the g-ratio in $\mathrm{B}_{\text {regs }}$-treated animals was comparable to the one observed in otherwise normal age- and gendermatched WT mice. These data are indicative of an increase in both remyelination and thickness of myelin on remyelinated axons after adoptive $B_{\text {regs }}$ transfer, implying an activation/ recruitment of endogenous OPCs. No differences were noticeable in the cervical region typically spared meaningful demyelination in actively ill EAE mice.

CNS resident microglia and monocytes/macrophages are key players in immune regulation of the CNS, neurogenesis, synaptic pruning, and by secreting growth factors, such as IL-10, and chemokines important for activation and migration of OPCs (Kremlev et al., 2004; Peferoen et al., 2014; Lloyd and Miron, 2019). In different neurologic disorders similar to what is observed in MS, microglia/macrophage activation has been 


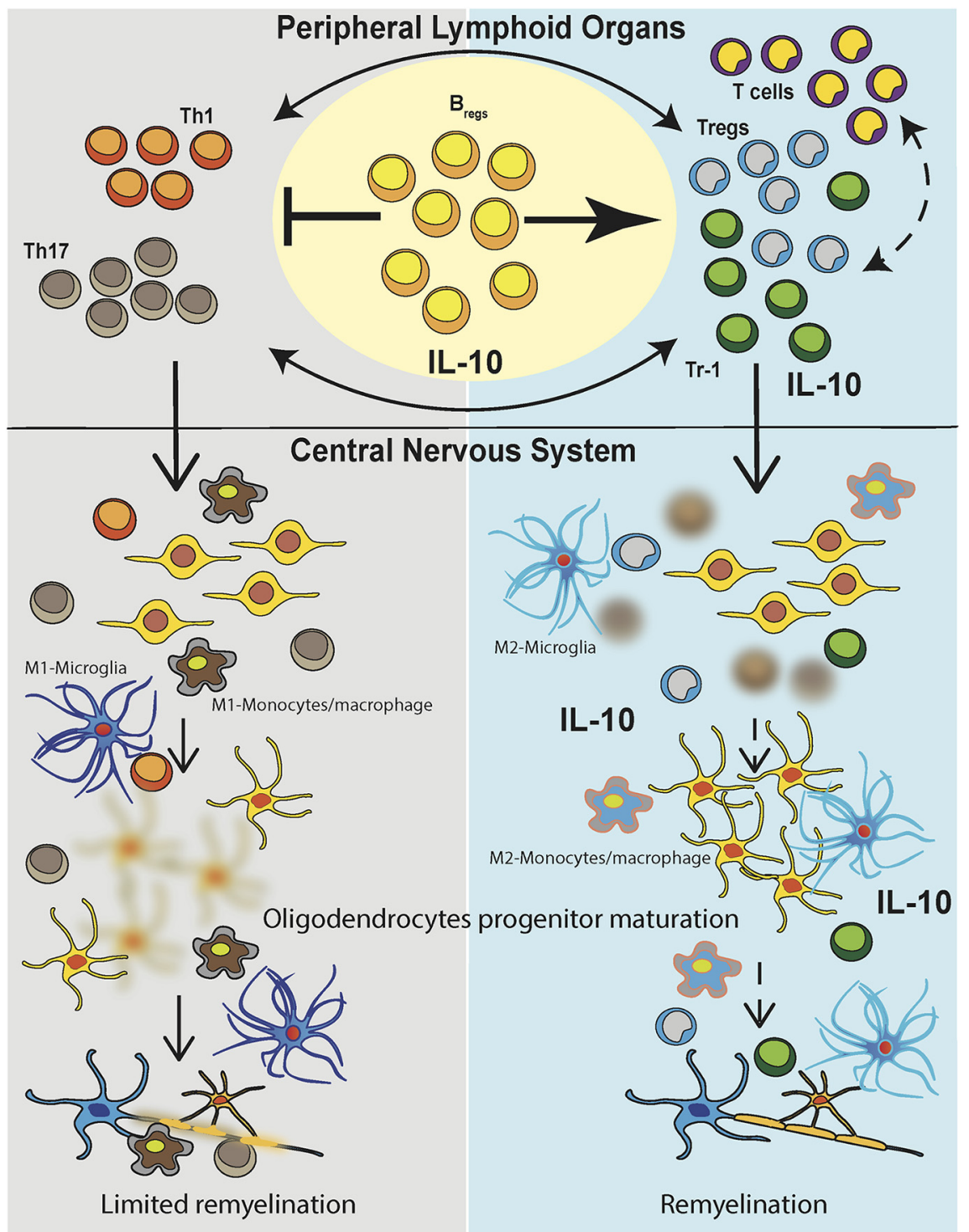

Figure 6. Model of repair process induced by $B_{\text {regs }}$ and effect in lymphoid organs and CNS. EAE manifested with an increase in autoreactive T cells and inflammation in lymphoid organs and the CNS causing demyelination and axon loss occur. In lymphoid organs, autoreactive T cells (Th1 and Th17) are induced after MOG immunization, and they then migrate in the CNS. The inflammatory microenvironment of the CNS induced demyelination and loss of oligodendrocytes. Myeloid-derived cells, both resident microglia and blood-derived monocytes/macrophages, showed a proinflammatory phenotype in B-celltreated mice compared with WT or $B_{\text {regs }}$-treated animals (left). Adoptive transfer of $B_{\text {regs }}$ can decrease the frequency of autoreactive T cell in the periphery and the CNS with concomitant increased of IL-10-producing T cells, both Tr-1 and canonical $\mathrm{T}_{\text {regs. }}$. Moreover, in mice that received $B_{\text {regss }}$ myeloid-derived cells, both monocytes/macrophages and microglia, displayed a more immunosuppressive phenotype, and their frequency is lowered respect to EAE mice (right). Concomitantly, a maturation/differentiation of OPCs was evident in the spinal cords of mice that received $B_{\text {regs }}$ concurrent with remyelination.

shown to lead to the secretion of proinflammatory cytokines (W. Y. Wang et al., 2015). Conversely, both macrophages and microglia appear to play a beneficial role in remyelination. In EAE mice, IL-4-activated microglia injected into the CSF induced oligodendrogenesis and improved clinical outcome of the diseases by sustaining CNS development (Butovsky et al., 2006). Indeed, OPCs and oligodendrocytes have been found to be responsive to many cytokines and chemokines, including IL-10, by the expression or their cognate immune receptors (Kremlev et al., 2004). We already reported in two distinct murine models of neurodegenerative disease that adoptive transfer of $\mathrm{B}_{\text {regs }}$ leads to CNS infiltration by IL- $10^{+} \mathrm{T}_{\text {regs }}$ and $\mathrm{Tr}-1$ providing a plausible source of a morphogen (e.g., IL-10) that may drive oligodendrogenesis. This phenomenon is further associated with a dramatically decreased frequency of infiltrating monocytes/macrophages in the CNS (Pennati et al., 2016, 2018). We found that EAE mice treated with $B_{\text {regs }}$ showed a decrease frequency of myeloidderived macrophages $\left(\mathrm{CD} 45^{\text {high }} \mathrm{CD} 11 \mathrm{~b}^{+}\right)$, both in brains and spinal cords as well as a significant decrease in resident microglia $\left(\mathrm{CD} 45^{\text {high }} \mathrm{CD} 11 \mathrm{~b}^{+} \mathrm{Ly} 6 \mathrm{C}^{-}\right)$in the spinal cords as well. Both CNS resident macrophages and microglia also displayed features consistent with M2-like polarization as reflected by CD206 expression. We showed that the adoptive transfer of $B_{\text {regs }}$ not only normalized the content of myeloid-derived cells in the CNS to levels comparable to that observed in the WT mice but polarized their phenotype to be immunosuppressive and more regenerative.

Interestingly, it has been found that polarization toward an M2 phenotype occurs in resident microglia and myeloid-derived macrophages in CNS lesion during remyelination (Miron et al., 2013). Moreover, our data indicate the importance of endogenous IL-10 for the remyelination process induced by $\mathrm{B}_{\text {regs }}$. Indeed, IL- $10^{-1-}$ mice not only developed a more severe form of EAE, but they were also unresponsive to IL-10-sufficient $B_{\text {regs }}$ treatment and did not show any amelioration of disease offset. These observations as well as our previous report that $B_{\text {regs }}$ leads to secondary homing of $\mathrm{IL}-10^{+} \mathrm{T}$ cells in CNS suggests that IL-10 derived from these CNS resident myeloid and lymphoid suppressor cells may be providing the impetus for OPC activation and remyelination following $B_{\text {regs }}$ transfusion.

During EAE, a general expansion of endogenous CNS-resident OPCs in the spinal cord has been documented in the early phases of the disease followed by a sequential expansion of late OPC populations (Robinson et al., 2014). However, full maturation of OPCs in EAE mice is partial and cannot fully repair myelin defects (Young et al., 2013). The partial remission of EAE is usually associated with decreased inflammation rather than remyelination. Indeed, OPCs collected from spinal cords of control B-cell-treated EAE mice did not express early OPC markers and showed only a partial overexpression of late progenitor O1 marker. This observation suggested the inability of these control animals to fully mature OPCs and remyelinate lesions in the spinal cord. In contrast, $B_{\text {regs }}$-treated EAE animals displayed significant expression of early OPC progenitor markers concurrent to full clinical remission.

Moreover, an upregulation of premyelinating oligodendrocytes markers, such as GalC and O1, was also observable in EAE mice treated with $\mathrm{B}_{\text {regs. }}$. In B-cell-treated mice, only $\mathrm{O} 1$ was upregulated after 3 weeks. This suggested the inability of these EAE animals to fully mature OPCs, and therefore properly 
remyelinate the lesions already created in the spinal cord. Similarly, $\mathrm{B}_{\text {regs }}$-treated animals showed higher expression of MBP during remyelination and remission of the disease as well an overexpression of MOG compared with untreated EAE mice and/or animals treated with B cells. In mouse, PRRX1 has been associated with neural progenitor cell self-renewal (Shimozaki et al., 2013) and in human upregulation induced quiescence of OPCs (J. Wang et al., 2018). Interestingly, PRRX1 expression was present only in normal mice and B-cell-treated animals. The treatment with $B_{\text {regs }}$ was able to fully downregulate the transcription factor. Treatment with $B_{\text {regs }}$ is most likely able to induce maturation and differentiation of OPCs similarly to what is observed in humans (J. Wang et al., 2018).

MS is the most common demyelinating disease of human adults (Ritzel et al., 2015). Treatments available are essentially immunosuppressive: they decrease the frequencies of relapses but do not affect disease progression or promote remyelination (Axisa and Hafler, 2016; Cree and Hartung, 2016; Hartung, 2017). The only investigational drug with early clinical evidence of promoting remyelination is the over-the-counter medication clemastine fumarate (Green et al., 2017). In a Phase II clinical trial (NCT02040298), the oral antihistamine modestly improved the transmission of electrical signals in the optic nerve. This effect was seen in 50 patients with remitting-relapsing MS who were experiencing chronic demyelinating optic neuropathy while on immunomodulating therapy. While the study with clemastine fumarate was a promising single-center study whose findings need to be confirmed on a larger scale, the development of remyelinating therapies for MS is indeed an urgent and unmet medical need (Green et al., 2017). By regenerating the myelin sheath around the axons, neuronal function can be fully restored and prevent further neuronal loss and clinical disability.

Our findings provide evidence that treatment of EAE mice with transfusion of syngeneic regulatory B cells not only altered the immune microenvironment within the CNS (myeloidderived cells and infiltrating lymphocytes) but also induced regeneration of myelin sheaths along the spinal column axons of $\mathrm{B}_{\text {regs }}$-treated mice (Fig. 6). Separate from traditional immune suppressive strategies that typically attempt to deplete or counteract the number and function of pathogenic lymphomyeloid cells, one can envision the use of autologous $B_{\text {regs }}$ to normalize CNS immune homeostasis by reshaping CNS endogenous activated immune cells and secondarily promoting remyelination by morphogen-activated OPCs.

\section{References}

Axisa PP, Hafler DA (2016) Multiple sclerosis: genetics, biomarkers, treatments. Curr Opin Neurol 29:345-353.

Azodi S, Nair G, Enose-Akahata Y, Charlip E, Vellucci A, Cortese I, Dwyer J, Billioux BJ, Thomas C, Ohayon J, Reich DS, Jacobson S (2017) Imaging spinal cord atrophy in progressive myelopathies: HTLV-I-associated neurological disease (HAM/TSP) and multiple sclerosis (MS). Ann Neurol 82:719-728.

Bove RM, Green AJ (2017) Remyelinating pharmacotherapies in multiple sclerosis. Neurotherapeutics 14:894-904.

Bradl M, Lassmann H (2010) Oligodendrocytes: biology and pathology. Acta Neuropathol 119:37-53.

Butovsky O, Landa G, Kunis G, Ziv Y, Avidan H, Greenberg N, Schwartz A, Smirnov I, Pollack A, Jung S, Schwartz M (2006) Induction and blockage of oligodendrogenesis by differently activated microglia in an animal model of multiple sclerosis. J Clin Invest 116:905-915.

Chamberlain KA, Nanescu SE, Psachoulia K, Huang JK (2016) Oligodendrocyte regeneration: its significance in myelin replacement and neuroprotection in multiple sclerosis. Neuropharmacology 110:633-643.
Cree BA, Hartung HP (2016) Steering through complexity: management approaches in multiple sclerosis. Curr Opin Neurol 29:263-271.

Dendrou CA, Fugger L, Friese MA (2015) Immunopathology of multiple sclerosis. Nat Rev Immunol 15:545-558.

Dimou L, Simons M (2017) Diversity of oligodendrocytes and their progenitors. Curr Opin Neurobiol 47:73-79.

Domingues HS, Cruz A, Chan JR, Relvas JB, Rubinstein B, Pinto IM (2018) Mechanical plasticity during oligodendrocyte differentiation and myelination. Glia 66:5-14.

Franklin RJ, Goldman SA (2015) Glia disease and repair-remyelination. Cold Spring Harb Perspect Biol 7:a020594.

Goldschmidt T, Antel J, Konig FB, Bruck W, Kuhlmann T (2009) Remyelination capacity of the MS brain decreases with disease chronicity. Neurology 72:1914-1921.

Green AJ, Gelfand JM, Cree BA, Bevan C, Boscardin WJ, Mei F, Inman J, Arnow S, Devereux M, Abounasr A, Nobuta H, Zhu A, Friessen M, Gerona R, von Budingen HC, Henry RG, Hauser SL, Chan JR (2017) Clemastine fumarate as a remyelinating therapy for multiple sclerosis (ReBUILD): a randomised, controlled, double-blind, crossover trial. Lancet 390:2481-2489.

Guy J, Ellis EA, Hope GM, Emerson S (1991) Maintenance of myelinated fibre $\mathrm{g}$ ratio in acute experimental allergic encephalomyelitis. Brain 114:281-294.

Hagemeier K, Bruck W, Kuhlmann T (2012) Multiple sclerosis: remyelination failure as a cause of disease progression. Histol Histopathol 27:277287.

Hartung DM (2017) Economics and cost-effectiveness of multiple sclerosis therapies in the USA. Neurotherapeutics 14:1018-1026.

Hemmer B, Kerschensteiner M, Korn T (2015) Role of the innate and adaptive immune responses in the course of multiple sclerosis. Lancet Neurol $14: 406-419$

Ingwersen J, Aktas O, Hartung HP (2016) Advances in and algorithms for the treatment of relapsing-remitting multiple sclerosis. Neurotherapeutics 13:47-57.

Kalincik T (2015) Multiple sclerosis relapses: epidemiology, outcomes and management. A systematic review. Neuroepidemiology 44:199-214.

Katz Sand I (2015) Classification, diagnosis, and differential diagnosis of multiple sclerosis. Curr Opin Neurol 28:193-205.

Kremlev SG, Roberts RL, Palmer C (2004) Differential expression of chemokines and chemokine receptors during microglial activation and inhibition. J Neuroimmunol 149:1-9.

Lemus HN, Warrington AE, Rodriguez M (2018) Multiple sclerosis: mechanisms of disease and strategies for myelin and axonal repair. Neurol Clin 36:1-11.

Lloyd AF, Miron VE (2019) The pro-remyelination properties of microglia in the central nervous system. Nat Rev Neurol 15:447-458.

Mann MK, Maresz K, Shriver LP, Tan Y, Dittel BN (2007) B cell regulation of $\mathrm{CD} 4{ }^{+} \mathrm{CD} 25^{+}$T regulatory cells and IL-10 via $\mathrm{B} 7$ is essential for recovery from experimental autoimmune encephalomyelitis. J Immunol 178:3447-3456.

Matsushita T, Yanaba K, Bouaziz JD, Fujimoto M, Tedder TF (2008) Regulatory B cells inhibit EAE initiation in mice while other B cells promote disease progression. J Clin Invest 118:3420-3430.

Miller SD, Karpus WJ, Davidson TS (2010) Experimental autoimmune encephalomyelitis in the mouse. Curr Protoc Immunol Chapter 15:Unit $15-11$.

Miron VE, Boyd A, Zhao JW, Yuen TJ, Ruckh JM, Shadrach JL, van Wijngaarden P, Wagers AJ, Williams A, Franklin RJ, Ffrench-Constant C (2013) M2 microglia and macrophages drive oligodendrocyte differentiation during CNS remyelination. Nat Neurosci 16:1211-1218.

Nicholson LB, Greer JM, Sobel RA, Lees MB, Kuchroo VK (1995) An altered peptide ligand mediates immune deviation and prevents autoimmune encephalomyelitis. Immunity 3:397-405.

Peferoen L, Kipp M, van der Valk P, van Noort JM, Amor S (2014) Oligodendrocyte-microglia cross-talk in the central nervous system. Immunology 141:302-313.

Pennati A, Deng J, Galipeau J (2014) Maltose-binding protein fusion allows for high level bacterial expression and purification of bioactive mammalian cytokine derivatives. PLoS One 9:e106724.

Pennati A, Ng S, Wu Y, Murphy JR, Deng J, Rangaraju S, Asress S, Blanchfield JL, Evavold B, Galipeau J (2016) Regulatory B cells induce 
formation of IL-10-expressing T cells in mice with autoimmune neuroinflammation. J Neurosci 36:12598-12610.

Pennati A, Asress S, Glass JD, Galipeau J (2018) Adoptive transfer of IL-10 $(+)$ regulatory $B$ cells decreases myeloid-derived macrophages in the central nervous system in a transgenic amyotrophic lateral sclerosis model. Cell Mol Immunol 15:727-730.

Rafei M, Wu JH, Annabi B, Lejeune L, Francois M, Galipeau J (2007) A GMCSF and IL-15 fusokine leads to paradoxical immunosuppression in vivo via asymmetrical JAK/STAT signaling through the IL-15 receptor complex. Blood 109:2234-2242.

Rafei M, Hsieh J, Zehntner S, Li M, Forner K, Birman E, Boivin MN, Young YK, Perreault C, Galipeau J (2009) A granulocyte-macrophage colonystimulating factor and interleukin-15 fusokine induces a regulatory $\mathrm{B}$ cell population with immune suppressive properties. Nat Med 15:1038-1045.

Ritzel RM, Patel AR, Grenier JM, Crapser J, Verma R, Jellison ER, McCullough LD (2015) Functional differences between microglia and monocytes after ischemic stroke. J Neuroinflammation 12:106.

Robinson AP, Rodgers JM, Goings GE, Miller SD (2014) Characterization of oligodendroglial populations in mouse demyelinating disease using flow cytometry: clues for MS pathogenesis. PLoS One 9:e107649.
Scolding NJ, Pasquini M, Reingold SC, Cohen JA, International Conference on Cell-Based Therapies for Multiple Sclerosis (2017) Cell-based therapeutic strategies for multiple sclerosis. Brain 140:2776-2796.

Shimozaki K, Clemenson GD Jr, Gage FH (2013) Paired related homeobox protein 1 is a regulator of stemness in adult neural stem/progenitor cells. J Neurosci 33:4066-4075.

Soelberg Sorensen P (2017) Safety concerns and risk management of multiple sclerosis therapies. Acta Neurol Scand 136:168-186.

Vidal-Jordana A, Montalban X (2017) Multiple sclerosis: epidemiologic, clinical, and therapeutic aspects. Neuroimaging Clin North Am 27:195-204.

Wang J, Saraswat D, Sinha AK, Polanco J, Dietz K, O’Bara MA, Pol SU, Shayya HJ, Sim FJ (2018) Paired related homeobox protein 1 regulates quiescence in human oligodendrocyte progenitors. Cell Rep 25:34353450.e3436

Wang WY, Tan MS, Yu JT, Tan L (2015) Role of pro-inflammatory cytokines released from microglia in Alzheimer's disease. Ann Transl Med 3:136.

Young KM, Psachoulia K, Tripathi RB, Dunn SJ, Cossell L, Attwell D, Tohyama K, Richardson WD (2013) Oligodendrocyte dynamics in the healthy adult CNS: evidence for myelin remodeling. Neuron 77:873-885. 